\title{
THE ENDANGERED LANGUAGES ISSUE AS A HOPELESS CAUSE*
}

\author{
PAUL NEWMAN \\ Department of Linguistics and West African Languages Institute, \\ Indiana University
}

\section{Introduction}

The figure often bandied about, taken from statements by Michael Krauss (1992), is that there are now some 6,000 languages in the world, half of which are likely to be lost within the present century. According to Krauss, the situam tion is even worse: of these 3,000 remaining languages, only 600 have a good chance of real survival over the long term, i.e., if the trend persists, some $90 \%$ of the world's languages will be lost. The question Krauss (1992:7) poses is: "What are we linguists doing to prepare for this or to prevent this catastrophic destruction of the linguistic world?"

if is only within the past ten or so years that linguists have begun to focus on this issue and to stress the point that the disappearance of languages and linguistic diversity is a major loss to linguistic scholarship and science. However, since the endangered languages issue was brought to the fore, it has caught the attention of the linguistics profession and has stimulated much activity. There have been a variety of conferences on the subject, both in America and in Europe, and a number of major publications have appeared, including Brenzinger (1998), Brenzinger, Heine \& Sommer (1991), Fishman (1991; 2001), Grenoble \& Whaley (1998), Matsumura (1998), and Robins \& Uhlenbeck (1991). The lead article in the March 1992 issue of Language,

\footnotetext{
"Acknowledgements: This is a revised version of an article originally published as, "'We has seen the enemy and it is us": The endangered languages issue as a hopeless cause", Studies in the Linguistic Sciences 28(2):11-20 (1998). The paper was first presented at a symposium on "The Linguistic Sciences in a Changing Context" organized by Braj Kachru, Adele Goldberg, and Jerry Morgan at the University of IIllinois (1998). The paper was subsequently the subject of a heated discussion at a workshop on endangered languages organized by Simon Donnelly at the LSA summer institute (1999).
} 
which was written by a group of distinguished linguists, was devoted to the endangered languages question (see Hale et al. 1992).

Even more striking has been the creation of organizations and activities devoted to the topic. For example, the Linguistic Society of America (LSA) has a standing Committee on Endangered Languages and their Preservation; there is a Foundation for Endangered Languages at the University of Bristol, UK, and an International Clearing House for Endangered Languages at the University of Tokyo. UNESCO is involved in the preparation of an Atlas of the World's Languages in Danger of Disappearing. Non-profit foundations are also springing up, e.g., the Endangered Languages Fund (New Haven) and Terralingua, Partnerships for Linguistic and Biological Diversity (Hancock, Michigan). In addition, the Lisbet Rausing Charitable Fund has recently given the University of London School of Oriental and African Studies (SOAS) a large grant to set up an Academic Project on Endangered Languages.

Although I think that Marianne Mithun (1998:163) is overstating it when she asserts, "At long last the tragedy of language loss worldwide has begun to enter the public conscious [sic]," it is true that awareness of the issue now extends beyond the narrow confines of professional linguists. Here one can cite the front page articles that appeared in the New York Times (Brooke 1998) and the Washington Post (Gugliotta 1999) and the short piece found in Newsweek (Raymond 1998).

My intention here is not to raise the question of why languages disappear (see Mufwene 1998; 2001). Nor do I want to get into the sensitive question of whether it makes any sense philosophically or practically to try to renew or revive dying languages (see Ladefoged 1992; Dorian 1993; Fishman 2001). Once one leaves the realm of emotional hand twisting by sentimental scholars, the question is much more debatable than appears at first sight.

However, I think that professional linguists can agree that the disappearance of a language without documentation is a huge scientific loss. Our linguistic scientific enterprise depends on the multiplicity of languages and the knowledge of linguistic diversity. It is only through knowledge of diverse languages with different structures and belonging to different language families that we can truly begin to gain an understanding of universal grammar, i.e., the nature of the human language capacity. Similarly, our understanding of linguistic typology and our ability to classify languages accurately and reconstruct proto-forms depends on the availability of a wide array of languages.

If one believes this, if one takes the position that no language should be allowed to become extinct without having been scientifically preserved, then one has to acknowledge that the task is urgent. Speakers of endangered lan- 
guages are not only dying away - the most obvious and final loss - but they are also forgetting their languages and losing command of the richness that defined that language as opposed to the one down the road. As Dixon (1997:147 note 5) correctly points out, "A sad lesson that has been leamt from the study of language-death situations is that a community does not realise its language is threatened until it is too late to do anything to remedy the situation."

Dixon's view about what needs to be done is stated in unequivocal terms (1997:144): "The most important task in linguistics today - indeed, the only really important task - is to get out in the field and describe languages, while this still can be done. Self-admiration in the looking glass of formalist theory can wait; that will always be possible. Linguistic description must be undertaken now."

Even if one puts some of the hyperbole aside, the truth is that the problem is real and we linguists are doing very little about it, apart from discussing the matter among ourselves so as to assuage our guilt. This is clearly a case where we cannot shift the blame to someone else: the failure to tackle the endangered languages crisis is not due to some budget dean nor to some philistine of a congressman nor to a CEO of some big corporation. The fault lies with us linguists, the people who should be up in ams about the problem. In essence, to quote from Pogo, the popular American comic strip created by Walt Kelley (1913-1973), "We has seen the enemy, and it is us."

What I shall do in this paper is discuss significant areas in which we as linguists exacerbate rather than solve the problem. The discussion falls under three headings: First, we linguists don't care; second, we linguists care too much; and third, our non-western colleagues don't care and would be unprepared to help out even if they did.

\section{We linguists don't care}

\subsection{Theory}

One hates to make blanket generalizations about a discipline as varied and with so many subfields as linguistics. Nevertheless, it is probably fair to say that in terms of overall world view and intellectual orientation, linguistics as a ficld is fundamentally theory driven as opposed to data driven. There was a time when linguistics was inextricably tied up with the study of non-written, non-western languages, but this is not the case today. General linguists aren't opposed to the study of these languages; it's just that it isn't important to them. What is viewed as important is trying to characterize the species-shared human language capability, i.e., linguistics has diverged from its anthropological and 
philological roots and has become in effect a branch of cognitive psychology. The lack of concern about the endangered languages problem is an extension of the general lack of interest in descriptive empirical research, whatever the language might be.

This lack of interest is reflected in the structure of graduate linguistics curricula, the content of linguistics courses at the introductory and advanced levels, and in professional hiring practices. The low valuation of fieldwork in our discipline is shown by the marginal position of field methods classes in most linguistics programs. (See Newman 1992 for a now out-of-date but probably still accurate compilation of departmental practices.) The appearance of two recent books on fieldwork (Vaux \& Cooper 1999; Newman \& Ratliff 2001) might be heartening and suggest a reawakening of interest in field linguistics. But against this one can point to the depressing fact that out of almost ninety different courses offered at the 2001 LSA Linguistics Institute in Santa Barbara, there was not a single course on field methods!

Someone might legitimately ask whether there is any objective evidence to document the claim that the empirical study of "exotic" languages occupies a minor position in linguistics. To check this out, I decided to look at the topic of $\mathrm{Ph}$.D. dissertations completed at American universities, since what students focus on is probably a reasonable reflection of the current ethos in a field and the interests of their teachers. The information was derived from an analysis of the linguistics section of Dissertation Abstracts International covering the period from January 1997 through December 2000, i.e., four years' worth of entries. Based primarily on the titles, with a quick glance at the abstracts themselves, I sorted the dissertations into a number of crude categories, defined both in terms of linguistic subfields, e.g., theoretical (English), computational linguistics, language acquisition (including second language learning), and sociolinguistics, or in terms of language families and geographical areas, e.g., Romance, Semitic, African, Native American, etc. Granted that the methodology was a bit haphazard and unsystematic, nevertheless the results were strikingly clear.

In the four years covered, there were a total of some 1,860 dissertations. Of these, 1,152 were concerned either with English, including English as a second language, or matters of a general linguistic or theoretical nature; 325 were on languages of Europe (including Turkish), of which 274 were on the big three, namely, Romance, Germanic, and Slavic; 215 were on Asian languages, most of which (192) were on Chinese, Japanese, or Korean; and 40 were on Semitic and Ancient Egyptian. These four macro-categories accounted for 1,732 of the dissertations, i.e., $93 \%$ of the total. That left a mere 128 dissertations (i.e., $7 \%$ ) devoted to the languages of Native America (51), Africa (41), Austronesia 
(including India) (33), and Australia (3). But even these 128 dissertations cannot all be said to represent fieldwork on small "exotic" languages, since (a) they include studies of major languages such as Malay, Hindi, Navajo, Hausa, and Swahili, and (b) some of these theses were theoretical studies drawing on secondary materials or descriptions of the student's own language. In short, $5 \%$ at most of the Ph.D. dissertations written during the past four years could be said to represent primary linguistic research involving significant fieldwork.

\subsection{The culture of linguists (as opposed to anthropologists)}

When linguistics was a part of anthropology, as it was for Boas, Lounsbury, Sapir, Voegelin, et al. (see Lounsbury 1968), fieldwork was a natural component of work in the discipline. Anthropology graduate students have traditionally been expected to go into the field; a student who wanted to do an "armchair" dissertation was viewed as a professional misfit. Crediting Kroeber, Geertz (1984:265) speaks of the "centrifugal impulse of anthropology - distant places, distant times, distant species ... distant grammars." Clearly there are problems with basing scholarly pursuits on the appeal of the "exotic" (consider, for example, the concerns expressed by Said 1978), but what is striking about linguistics nowadays as opposed to anthropology is its almost total separation from fieldwork. My personal experience with linguistics graduate students over the years is that they display a singular lack of venturesomeness. Students aren't attracted by the idea of fieldwork for the simple reason that they don't want to go to the field. I suspect, that if I had funding to send a dozen graduate students to remote places to do research on dying languages, I would have trouble giving the money away. The students whom I have met would much rather stay in the comfort of a university setting working within the confines of the latest (and thus non-risky) linguistic theory than undertake basic descriptive research, i.e., they have no desire to subject themselves to the practical rigors and intellectual uncertainties and frustrations of fieldwork (see Hyman 2001). Dixon's charge to linguists to get out into the field will fall on deaf ears because it runs counter to the prevailing culture and personality of the people who now make up the discipline of linguistics.

\section{We linguists care too much}

When Emmon Bach, a well-known and distinguished theoretical linguist, was working on Wakashan, an endangered language of British Columbia, he was challenged by one of the elders as to why he and members of his community should care about the linguistic work that was being done. Bach's response was to formulate the following principle (Bach 1995): "I will try to put at least half of my time and effort in working in a community into things that 
make sense for the community. What that work might be can range from things as simple as copying tapes for people who want them, through preparing texts, etc. in ways that are accessible, to helping out with language programs, etc." This quotation has subsequently been repeated with approbation and without a hint of challenge - by any number of linguists.

Whereas fieldwork does entail real ethical and professional responsibilities to the people whose language one is studying (see Greaves 1994; Newman 1992), I am troubled by the notion that researchers have an obligation to spend half of their time doing what I would call linguistic social work. I know that this is an unfashionable position nowadays, but I would argue that there is value in pure basic research and that as scientists we have to resist the everpresent pressure to justify our work on grounds of immediate social relevance. The primary justification for doing research on an endangered language has to be the scientific value of providing that documentation and in preserving aspects of that language and culture for posterity. The purpose cannot be to make the few remaining speakers feel good.

Having said this - and fundamentally I do believe strongly in the correctness of this viewpoint - the reality is that it is impossible to escape the practical and emotional pressures to behave like a caring human being in the field, nor would one want to (see Grinevald 1998:157). In many cases, languages are dying because communities are dying, and they are often dying because they are poor and have been neglected, if not directly exploited. The linguist who is welcomed into such a situation will either fail to establish rapport, in which case the research will be a failure, or will establish rapport, in which case he or she will increasingly acquire social and professional responsibilities that will compete for research time. The result is that the good-hearted, well-meaning linguist, to whom we can all extend our admiration, will do less of a job of basic documentation than one would have hoped for.

One might argue that in the case of endangered languages, the intertwining of language preservation as a social goal and language documentation as a scientific goal is, if not beneficial, at least harmless. I think otherwise.

To begin with, language preservation projects drain resources from the important linguistic task of primary documentation, both in terms of personnel and in terms of research funds. An example that for me is close to home is the important American Indian Studies Research Institute at Indiana University. Over the past years, this Institute, which is staffed by a number of technically competent and highly motivated linguists, has devoted a major portion of its efforts into designing and preparing language teaching materials in Native American languages for use in the schools. These materials (for example, the ones on Arikara) are truly impressive; they are masterfully done with beautiful 
typography and excellent graphics, accompanied by interactive recordings. The negative side, however, is that manpower that could have been spent working on basic linguistic description of endangered languages has been occupied with what are essentially ethnic awareness, cultural heritage projects.

One cannot deny that socially relevant issues like language survival/revival have more "sex appeal" than pure linguistic documentation. As a result, preservation projects are bound to be given preference by funding agencies, especially when large groups that have political visibility and can speak out for themselves are involved. A few years ago, for example, the Administration for Native Americans announced the availability of substantial grants (up to $\$ 125,000$ per year for three years) in support of projects that would "promote the survival and continuing vitality of Native American languages" and encourage the "establishment and support of community Native American language projects to bring older and younger Native Americans together to facilitate and encourage the transfer of Native American language skills from one generation to another . .." (e-mail distribution from SMARTS grantline, 1998). Given the paucity of funds for linguistic research, one can understand why linguists would be attracted to apply for such grants and if successful would gladly embark on the work. But, the reality is that the Administration for Native Americans is not going to fund revival projects on essentially moribund languages spoken by the last three or four octogenarians - the money is much more likely to go to support seemingly viable languages such as Navajo and Lakota. Moreover, even if funds were to be provided for work with truly endangered languages, which would be unlikely, the applied nature of the projects and the extent of commitments to the relevant communities would leave almost no time for whatever pure research the linguist might hope to carry out on the side.

Once one leaves the realm of North America, there is also a troublesome question regarding the appropriateness of activist policies regarding preservation and revitalization of minority languages. A westerner who gets permission to conduct basic linguistic research in Africa (or Asia or Latin America) is a guest in someone else's country, one who has been allowed to go there for specific scholarly purposes. Language policy in fragile multi-ethic states is not a simple sociolinguistic matter; rather, it is a serious, highly contentious political matter with which a foreigner should not become embroiled. This is especially a problem because in many cases the cause of the language endangerment is not the spread of some European colonial language, but rather the spread of large indigenous languages. For example, in many parts of Africa, "big-population, officially and functionally recognised languages ... constitute a threat to small-population languages because their speakers are the power 
brokers and decision makers. Thus they make decisions that favour big languages and threaten the very existence of small ones" (Adegbija 2001:286).

If as part of its educational and economic policy, a country such as Nigeria should choose to promote its big languages (e.g., Hausa, Yoruba, and Igbo) at the expense of the "minor" ones, the western linguist who takes a "proactive" role in defense of the smaller, endangered languages is not only being presumptuous but is also being personally reckless, thereby risking the continuation and success of the field research project, not to mention his or her own safety and welfare. As linguists, we can attempt to educate and inform responsible persons in government, education, and business about the significance and value of linguistic diversity in their countries, but we have no right to intervene in domestic policy matters nor to undertake linguistic social work under the guise of scientific research.

\section{Our non-western colleagues don't care and would be unprepared to help out even if they did}

We are now in the $21^{\text {st }}$ century, but generally speaking we American (and European) linguists function in many ways as if it were 1960 or 1940 or even 1920. That is to say, although languages are dying in Brazil and India and Nigeria and Indonesia, we operate as if both the problem and the solution were ours and not that of the Brazilians, the Indians, the Nigerians, or the Indonesians. We're way off the mark. As active practitioners in the discipline of linguistics, with all the rights and interests and responsibilities thereof, our international colleagues should have been brought into the endangered languages fold, but unfortunately they have not.

Colette Grinevald (1998:151) has written: "To accept the fact that South American linguistics should be carried out as much as possible by South Americans has in fact deep implications for the way we conduct our business and the way we basically conceive of our role as linguists." One could argue whether this necessarily "should" be the case, but for very real practical matters, this has to be the case, and part of our inability to address the endangered languages problem in any meaningful way is due to the failure to recognize this point. Even if we - by which I again mean we Americans and western Europeans - had the will to carry out the needed empirical research on endangered languages around the world, there is no way that we could do it because of political and economic impediments. Most scholars are fully aware of the political and social realities of working in the developing world, namely the persistent hostility to foreign researchers. In many countries, it is a major hassle to get a visa, not to mention official permission to conduct research, and even if these are forthcoming, there are problems in getting in-country coop- 
eration and support. A more serious problem, however, is research funding: it just costs too much money for an American scholar to go abroad to carry out field research. One might be lucky in getting funds for one person to work one year on one endangered language, but who is going to attend to the other ten or twenty or thirty languages? The only way endangered languages in Africa, for example, are going to get described is if African linguists and their African students do the work. Otherwise it cannot get done.

In some sense, linguistics in the African area, to which I will limit myself for purposes of the discussion, is already falling into the hands of Africans. Anyone who now attends the Annual Conference on African Linguistics (which has been going on now for over thirty years) cannot help be struck by the shift in the balance of the participants as opposed to twenty or so years ago. At that time, most of the participants were white (and white male at that!); nowadays Africans, some of whom are established scholars, many with permanent positions in the U.S., others of whom are Ph.D. students, generally constitute at least half of the attendees.

Further evidence of the importance of Africans in African linguistic research can be gathered by looking at $\mathrm{Ph} . \mathrm{D}$. dissertations produced over the past decade. A convenient source here is the list published regularly in the $A S A$ (=African Studies Association) Newsletter, which includes theses from Canada and the United Kingdom as well as the United States. (This listing is more inclusive than that provided in Dissertation Abstracts International, which was analyzed above.) The entries from January 1990 through December 2000 provide a total of 145 theses on African languages and linguistics. Interestingly, 92 (over 60\%) of the theses were by Africans whereas 53 (under 40\%) were by non-Africans.

At first sight, these figures might appear to be promising and suggest that there is a new generation of young African scholars emerging who can undertake the fieldwork that needs to be done. However, there is a factor of real significance for the endangered languages question that does not appear in the raw numbers. When one looks at the languages treated by the African Ph.D. students, it turns out that almost all of the theses are descriptions of the writer's own language. There is the occasional exception - and one cannot be sure in all cases since the claim is based on surmise depending on the authors' names - nevertheless, based on the many instances where the authors are easily identified, there is good reason to believe that the exceptions are rare indeed. Typically when it comes to African Ph.D. students, a native speaker of Yoruba writes on Yoruba, a Wolof speaker writes on Wolof, and a Xhosa speaker writes on Xhosa. In most cases, the writer serves almost exclusively as her or his own informant. There is nothing intrinsically wrong with native 
speakers working on their own languages - and for many purposes it is of tremendous linguistic value - but one has to face the fact that little or no fieldwork was involved in the research leading to the preparation of the Ph.D. dissertation. In effect, having said that the study of endangered languages in Africa has to be done by Africans, we find that our African colleagues are no more qualified, no more trained, and no more ready to undertake the task than the most abstract, theoretically-oriented linguist.

Assuming, as I do, that this is a most unfortunate state of affairs, we have to ask, "What went wrong?" I would suggest that we western linguists have unwittingly distorted the intellectual development and orientation of nonwesterners studying in the United States (and Europe) with the result that we have excluded them from involvement in empirical descriptive linguistics in general and in the endangered languages issue in particular.

For an African to write on her own language, e.g., for an Igbo speaker to do a dissertation on Igbo, is essentially the same as for an English speaker to write on English. We descriptive field linguists who have little patience with the English speaking Ph.D. student who does the umpteenth study of reflexives or what have you in English - obviously in light of the latest ephemeral theory - have failed to recognize that what characterizes our work is the excitement of discovery with regard to a language that is outside of ourselves, and that the Igbo linguist who writes on Igbo is not partaking of the same enterprise. Those of us who are quick to say, "Who needs another study of English?" or "Why can't that person go to the field and do something of real value such as describing a poorly known language?" never pass judgment on our African students for what they are doing. We forget that whereas Igbo may be exotic for us, it is not for the Igbo speaker.

By allowing African students to work exclusively on their own languages, we fail to communicate the real nature, not to mention the importance, of fieldwork, which is essential if the person is ever going to do basic research when he returns home. In effect, we never encourage or cajole our African students who speak major languages such as Hausa, Yoruba, Lingala, or Swahili that what they must do when they finish their degrees and return home is undertake the study of minority languages and, moreover, that they must pressure their own students in their home universities to do the same. Since we don't require that they do first-hand research on other (small) African languages when they are students, how can we expect them to do such work later?

For a variety of reasons, the foreign students attending universities and studying linguistics (whether in their own countries or abroad) are rarely members of these minority communities themselves; it is people from the 
dominant groups who most often have these opportunities. Thus, in the absence of visionary scholars who fervently believe that language loss is indeed a culturally and intellectually catastrophic matter, language centers in Africa (and Asia and Latin America) will continue to devote their energies to the promotion and development of large national and regional languages, with scant attention to the languages that are speeding towards extinction.

Apart from the matter of attitude is the fact that we here in America do not properly train our African students in fieldwork procedures. Since most of our African Ph.D. students are writing on their own languages, generally using themselves as informants, we fail to give them instruction in empirical scientific methodology. They are not given solid training in phonetic transcription witness the fact that those who do not speak a tone language, and even many who do, are seldom trained in hearing and transcribing tone. They are not taught how to manage a corpus (since they are basing their theses on personal introspection) nor how to elicit and preserve primary data. In addition they are not taught how to collect and transcribe texts nor what one should do with them once they are available. In short, even if we could convince our African colleagues of the seriousness of the endangered languages question, the impractical $\mathrm{Ph} . \mathrm{D}$. education that we have provided them, with its heavy dose of modern linguistic theory and elegant formalism, has not equipped them to undertake the task.

\section{Conclusion}

I am afraid that I have to close on a somber note. Despite the best intentions of many well-meaning and dedicated linguists, the rapid disappearance of languages throughout the world is likely to continue unabated. Those of us who are concerned about the endangered languages question and the problem of language extinction are up against a formidable enemy - and that enemy is our own discipline of linguistics and the individuals who make it up. We can continue to talk about the matter, as surely will be done ad naiuseam at one international meeting or workshop after another; but given the odds against us, the chances of concrete results are pitifully small.

\section{References}

Adegbija, E. 2001. "Saving threatened languages in Africa: A case study of Oko". Fishman 2001. 284-308.

Bach, Emmon. 1995. Posting. Linguist List (posting 12 February 1995).

Brenzinger, Matthias. 1998. Endangered languages in Africa. Cologne: Rüdiger Köppe. 
-, Bemd Heine \& Gabriele Sommer. 1991. "Language death in Africa". Robins \& Uhlenbeck 1991. 19-44.

Brew, J.O., ed. 1968. One hundred years of anthropology. Cambridge, Mass.: Harvard University Press.

Brooke, James. 1998. "Indians striving to save their languages". New York Times, April 9, A1, A20.

Dixon, R. M. W. 1997. The rise and fall of languages. Cambridge: Cambridge University Press.

Dorian, Nancy C. 1993. "A response to Ladefoged's other view of endangered languages". Language 69. 575-79.

Fishman, Joshua A. 1991. Reversing language shift: theoretical and empirical foundations of assistance to threatened languages. Clevedon: Multilingual Matters.

-, ed. 2001. Can threatened languages be saved? Clevedon: Multilingual Matters.

Geertz, Clifford. 1984. "Distinguished lecture: anti anti-relativism". American Anthropologist 86. 263-78.

Greaves, Tom, ed. 1994. Intellectual property rights for indigenous peoples: a sourcebook. Oklahoma City: Society for Applied Anthropology.

Grenoble, Lenore A. \& Lindsay J. Whaley, eds. 1998. Endangered languages: current issues and future prospects. Cambridge: Cambridge University Press.

Grinevald, Colette. 1998. "Language endangerment in South America: a programmatic approach". Grenoble \& Whaley 1998. 124-59.

Gugliotta, Guy. 1999. "Saying the words that save a culture". Washington Post, August 9, Al A8.

Hale, Kenneth et al. 1992. "Endangered languages". Language 68. 1-42.

Hyman, Larry M. 2001. "Fieldwork as a state of mind". Newman \& Ratliff 2001. 15-33.

Krauss, Michael. 1992. "The world's languages in crisis". Language 68. 4-10. Ladefoged, Peter. 1992. "Another view of endangered languages". Language 68. 809-11.

Lounsbury, Floyd G. 1968. "One hundred years of anthropological linguistics". Brew 1968. 153-225.

Matsumura, Kazuto, ed. 1998. Studies in endangered languages. Papers from the international symposium on endangered languages, Tokyo, November 18-20, 1995. Tokyo: The Intemational Clearing House for Endangered Languages, University of Tokyo.

Mithun, Marianne. 1998. "The significance of diversity in language endangerment and preservation". Grenoble \& Whaley 1998. 163-91. 
Mufwene, Salikoko S. 1998. "The ecology of languages: new imperatives in linguistics curricula". Studies in the Linguistic Sciences 28:2. 135-45. -. 2001. The ecology of language evolution. Cambridge: Cambridge University Press.

Newman, Paul. 1992. "Fieldwork and field methods in linguistics". California Linguistic Notes 23:2. 1-8.

_ \& Martha Ratliff, eds. 2001. Linguistic fieldwork. Cambridge: Cambridge University Press.

Raymond, Joan. 1998. "Say what? Preserving endangered languages". Newsweek, September 14, 14.

Robíns, Robert H. \& Eugenius M. Uhlenbeck, eds. 1991. Endangered languages. Oxford and New York: Berg.

Said, Edward W. 1978. Orientalism. New York: Pantheon Books.

Vaux, Bert \& Justin Cooper. 1999. Introduction to linguistic field methods. Munich: LINCOM Europa. 